\title{
A Long-term Follow-up of Mandibular Deviation Caused by Congenital Cervical Lymphangioma Treated with an Orthodontic Approach
}

\author{
Akiko Mino-Oka ${ }^{1}$, Shinya Horiuchi ${ }^{2}$, Rie Matsuda ${ }^{3}$, Ryoko Shioyasono ${ }^{4}$, Mohannad Ashtar ${ }^{5}$, Masahiro Hiasa ${ }^{6}$, Akihiro Yasue ${ }^{7}$, \\ Keiji Moriyama ${ }^{8}$, Eiji Tanaka ${ }^{9}$
}

\begin{abstract}
Aim: To report a treatment case of mandibular deviation caused by congenital cervical lymphangioma with traditional orthodontic techniques, following-up by 10 -year retention.

Background: Lymphangiomas, developmental anomalies, can induce various disturbances of swallowing, mastication, speech, breathing, and skeletal deformities as well as psychological stress and anxiety for the patient and their family. Lymphangiomas are benign with virtually no possibility of turning into a malignant lesion, so clinical management aims to treat the patient functionally.

Case description: A girl, aged 6 years and 4 months, complained about facial asymmetry and anterior crossbite caused by congenital cervical lymphangioma. Her facial profile was the straight type with an adequate lip position. Anterior and right-side posterior crossbites were observed. On the frontal cephalogram, the menton shifted $3.0 \mathrm{~mm}$ to the right. A functional appliance with an expander was placed to correct her dental midline deviation and posterior crossbite. After 2-year treatment, the anterior and right-side posterior crossbites were improved. Multibracket treatment began after the growth spurt. After 44-month active treatment, a functional occlusion, including a Class I molar relationship with a proper interincisal relationship, was achieved. A functional occlusion was maintained during a 10-year retention period, while a mandibular downward growth was observed through the retention period.
\end{abstract}

Conclusion: Conventional orthodontic techniques enable functional and stable occlusion even in patients with mandibular deviation caused by congenital cervical lymphangioma, although only using early orthodontic management by itself may have some limitations.

Clinical significance: The hybrid technique combining functional appliance and intermaxillary elastics proves to be an effective therapy for correcting occlusal cant and mandibular deviation caused by cervical lymphangioma.

Keywords: Cervical lymphangioma, Conventional orthodontic treatment, Long-term follow-up, Mandibular deviation.

The Journal of Contemporary Dental Practice (2021): 10.5005/jp-journals-10024-3115

\section{INTRODUCTION}

Lymphangiomas are developmental anomalies that are quite uncommon. Although these malformations can arise anywhere in the lymphatic system, ${ }^{1,2}$ lymphangiomas mainly begin in the head and neck regions, and most cases (80-90\%) appear by the age of 2 years. As a matter of fact, they can often be diagnosed before birth via fetal ultrasonography, and if it appears after birth, it can be diagnosed via a histopathologic inspection. ${ }^{3}$ The main cause of lymphangioma is a blockage that occurs in the lymphatic system while the fetus is growing, but symptoms may only appear at some point after birth. However, the cause of such blockage has not been fully understood. ${ }^{4}$

Lymphangiomas in the head and neck regions can induce various disturbances of swallowing, mastication, speech, breathing, and skeletal deformities as well as psychological stress and anxiety for the patient and their family. ${ }^{5,6}$ In most cases, lymphangiomas are benign with virtually no possibility of turning into a malignant lesion, so clinical management aims to treat the patient functionally. Previously, several case reports have been published in which the patient with open bite involved in lymphangioma of the tongue was treated with early reduction of tongue volume and nonsurgical orthodontic treatment. ${ }^{5,7}$ However, since the interceptive orthodontic treatment of patients with cervical lymphangioma is
${ }^{1-4,7}$ Department of Orthodontics and Dentofacial Orthopedics, Tokushima University Hospital, Tokushima, Japan

${ }^{5}$ Department of Orthodontics and Dentofacial Orthopedics, Tokushima University Graduate School of Oral Sciences, Tokushima, Japan

${ }^{6}$ Department of Orthodontics and Dentofacial Orthopedics, Institute of Biomedical Sciences, Tokushima University Graduate School, Tokushima, Japan

${ }^{8}$ Department of Maxillofacial Orthognathics, Tokyo Medical and Dental University, Tokyo, Japan

${ }^{9}$ Department of Orthodontics and Dentofacial Orthopedics, Institute of Biomedical Sciences, Tokushima University Graduate School, Tokushima, Japan; Department of Orthodontics, King Abdulaziz University, Jeddah, Kingdom of Saudi Arabia

Corresponding Author: Eiji Tanaka, Department of Orthodontics and Dentofacial Orthopedics, Institute of Biomedical Sciences, Tokushima University Graduate School,Tokushima, Japan, Phone:+81-88-6337356, e-mail: etanaka@tokushima-u.ac.jp

How to cite this article: Mino-Oka A, Horiuchi S, Matsuda R, et al. A Long-term Follow-up of Mandibular Deviation Caused by Congenital Cervical Lymphangioma Treated with an Orthodontic Approach. J Contemp Dent Pract 2021;22(6):713-720.

Source of support: Nil

Conflict of interest: None

(c) Jaypee Brothers Medical Publishers. 2021 Open Access This article is distributed under the terms of the Creative Commons Attribution 4.0 International License (https://creativecommons.org/licenses/by-nc/4.0/), which permits unrestricted use, distribution, and non-commercial reproduction in any medium, provided you give appropriate credit to the original author(s) and the source, provide a link to the Creative Commons license, and indicate if changes were made. The Creative Commons Public Domain Dedication waiver (http://creativecommons.org/publicdomain/zero/1.0/) applies to the data made available in this article, unless otherwise stated. 
subjected to inefficient and considerably lower outcomes, there are few detailed reports of long-term observation through total orthodontic treatment.

The purpose of this case report is to present an adolescent case of mandibular deviation involved in congenital cervical lymphangioma treated with traditional orthodontic techniques and monitored for a long-term follow-up.

\section{Case Description}

A girl, aged 6 years and 4 months, complained about her facial asymmetry and reversed occlusion. She was diagnosed with cervical cystic lymphangioma at birth. She underwent partial excision twice to reduce the lymphangioma by the time she was 1-year-old. Complete surgical excision of the cystic lesions had been difficult because of the severe infiltration of lymphangioma into the surrounding muscle fibers. At the time of the first visit to the orthodontic department, she had an asymmetrical frontal view with swelling around her left glandula parotis (Fig. 1A). Her facial profile was the straight type with an adequate lips position. She had regular checkups of her lymphangioma by pediatricians and plastic surgeons. Anterior and right-side posterior crossbites were observed, and the terminal planes were a mesial step type on the left side and a vertical type on the right side (Fig. 1B). The overjet was $-0.5 \mathrm{~mm}$ and the overbite was $\pm 0 \mathrm{~mm}$.

The mandibular dental midline deviated $5.5 \mathrm{~mm}$ to the right, although the maxillary dental midline was almost matched up to the facial one (Fig. 1C). Several carious lesions were present in her dentition. The panoramic radiograph showed marked asymmetry of the mandibular angle (Fig. 1D). From the cephalometric analysis, ${ }^{8}$ she exhibited a skeletal Class I jaw-base relationship $\left(\right.$ ANB,$+4.8^{\circ}$ ) (Fig. 1C and 2A; Table 1). The mandibular plane had a normal inclination (FMA, $31.0^{\circ}$ ). The inclination of the mandibular central incisors was also within the normal range; however, frontal cephalometric analysis showed a $1^{\circ}$ occlusal cant, and her menton shifted $3.0 \mathrm{~mm}$ to the right.

\section{Treatment Objectives}

The patient was diagnosed with mandibular deviation caused by congenital cervical lymphangioma. When the tumor grows significantly, the patient may need surgical excision. Thus, we carefully followed up on her cystic lympahngioma. The treatment objectives were to (1) control the maxillo-mandibular growth during her growth period; (2) correct the anterior and posterior crossbite; and (3) accomplish a functional and stable occlusion with a proper interincisal relationship. In the first phase, to improve posterior crossbite caused by the cystic lesion, a functional appliance with expander was used and we carefully followed up during her growth. The second phase would include multibracket treatment to correct the remaining dentoalveolar discrepancies with non-extraction or extraction plans.

\section{Treatment Alternatives}

One treatment option-after observing her mother's Class III profile-was to wait until the end of the patient's mandibular growth and perform a surgical-orthodontic treatment. However, it is impossible to accurately predict how large the cervical lymphangioma could get; therefore, if the cystic hygroma was to get larger and come close to arteries or nerves, the orthognathic surgery may become impossible due to the risk of infection and effusion of hemorrhage. Furthermore, the patient and her parents
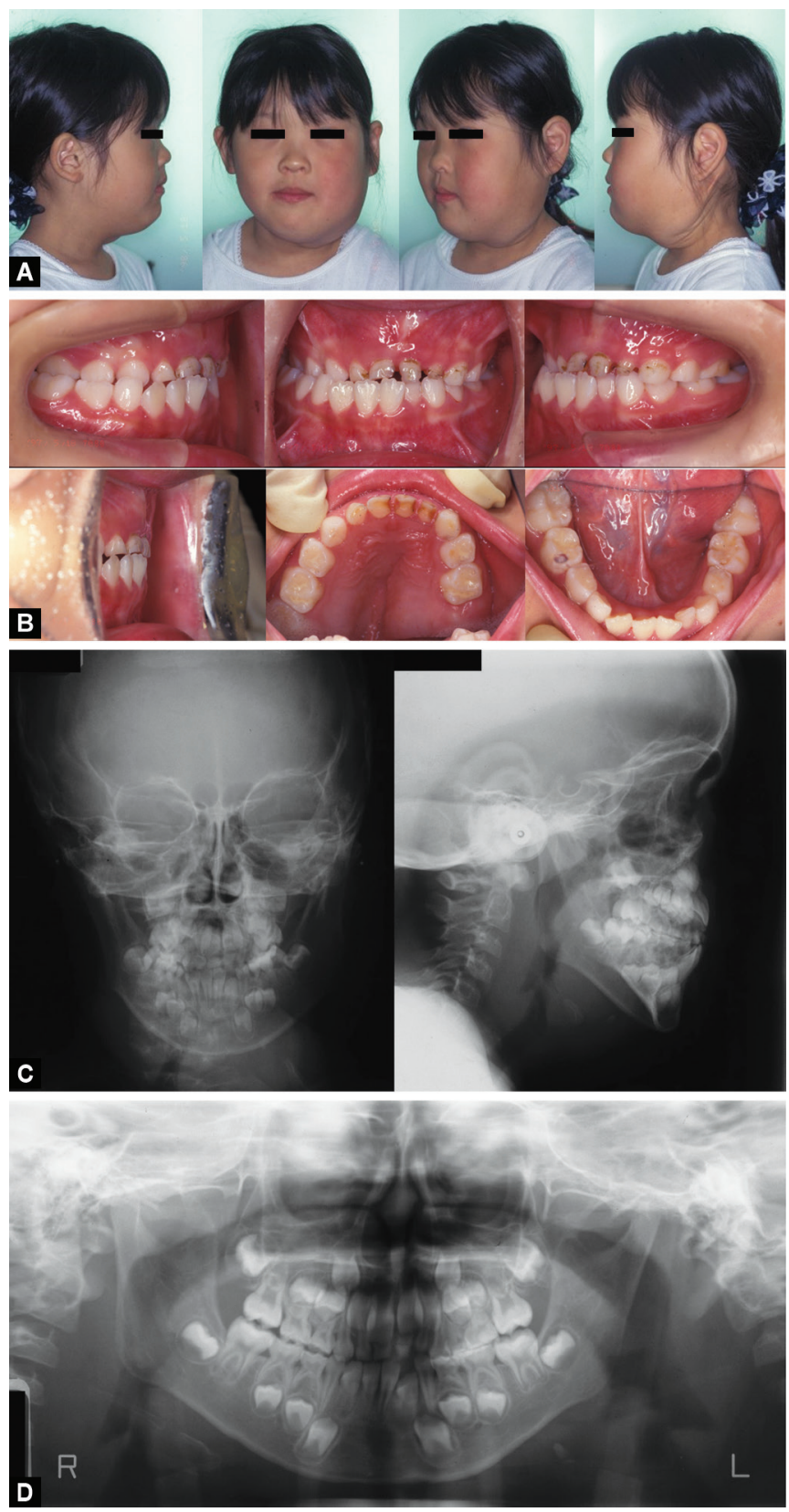

Figs $1 \mathrm{~A}$ to $\mathrm{D}$ : Pretreatment facial (A) and intraoral photographs (B), frontal and lateral cephalograms (C), and panoramic radiograph (D) (patient age, 6 years 4 months)

requested to avoid surgical treatment and to try to improve her facial esthetics and oral function as much as possible by orthopedic treatment with functional appliance.

\section{Treatment Progress}

The patient, aged 6 years and 11 months, started to use a functional appliance with expander for at least 10 hours/day to minimize the mandibular deviation and improve the posterior crossbite (Fig. 2B). After 2 years of treatment, the anterior and right-side posterior crossbite was improved; however, the maxillary lateral incisors erupted palatally, resulting in a reversed occlusion. Then, a lingual arch was set on the maxillary arch to correct the reversed occlusion of the maxillary lateral incisors. After the first phase 
Table 1: Cephalometric summary

\begin{tabular}{|c|c|c|c|c|c|c|c|c|}
\hline & $\begin{array}{l}\text { Mean for Japanese } \\
\text { female* } \\
\text { 6-year-old (SD) }\end{array}$ & Pretreatment & $\begin{array}{l}\text { Mean for Japanese } \\
\text { female* } \\
\text { 12-year-old (SD) }\end{array}$ & $\begin{array}{l}\text { After first } \\
\text { phase }\end{array}$ & $\begin{array}{l}\text { Mean for Japanese } \\
\text { female* } \\
\text { Adult (SD) }\end{array}$ & Posttreatment & $\begin{array}{l}\text { 3-year } \\
\text { retention }\end{array}$ & $\begin{array}{l}10 \text {-year } \\
\text { retention }\end{array}$ \\
\hline SNA & $80.7(3.4)$ & 82.5 & $80.8(3.6)$ & 81.6 & $80.7(3.4)$ & 84.1 & 84.1 & 84.1 \\
\hline SNB & $76.9(2.4)$ & 77.7 & $77.9(4.5)$ & 80.3 & $77.6(4.2)$ & 82.4 & 82.9 & 83.3 \\
\hline ANB & $3.7(2.0)$ & 4.8 & $2.8(2.4)$ & 1.2 & $3.0(2.2)$ & 1.7 & 1.2 & 0.8 \\
\hline FMA & $32.2(3.7)$ & 31.0 & $30.5(3.6)$ & 35.1 & $29.6(3.4)$ & 32.4 & 32.9 & 34.9 \\
\hline Gonial angle & $128.0(5.0)$ & 137.4 & $122.1(5.3)$ & 137.4 & $122.9(4.4)$ & 135.5 & 135.8 & 136.4 \\
\hline U1-FH pl. & $104.8(5.4)$ & 94.7 & $112.2(8.0)$ & 122.0 & $112.3(8.3)$ & 123.1 & 123.3 & 123.6 \\
\hline L1- Mand. PI. & $92.1(5.5)$ & 83.9 & $93.4(6.8)$ & 70.5 & $92.5(5.4)$ & 82.9 & 83.7 & 81.6 \\
\hline Interincisal angle & $124.8(5.8)$ & 150.3 & $123.6(10.6)$ & 132.5 & $125.1(10.1)$ & 121.6 & 120.1 & 119.9 \\
\hline Overjet (mm) & $2.6(1.2)$ & -0.5 & $3.2(1.0)$ & 1.0 & $3.1(1.1)$ & 2.3 & 2.0 & 2.0 \\
\hline Overbite (mm) & $2.4(1.7)$ & 0.0 & $3.6(2.0)$ & 1.4 & $3.3(1.9)$ & 1.3 & 1.2 & 1.2 \\
\hline
\end{tabular}

"Wada et al. ${ }^{8}$
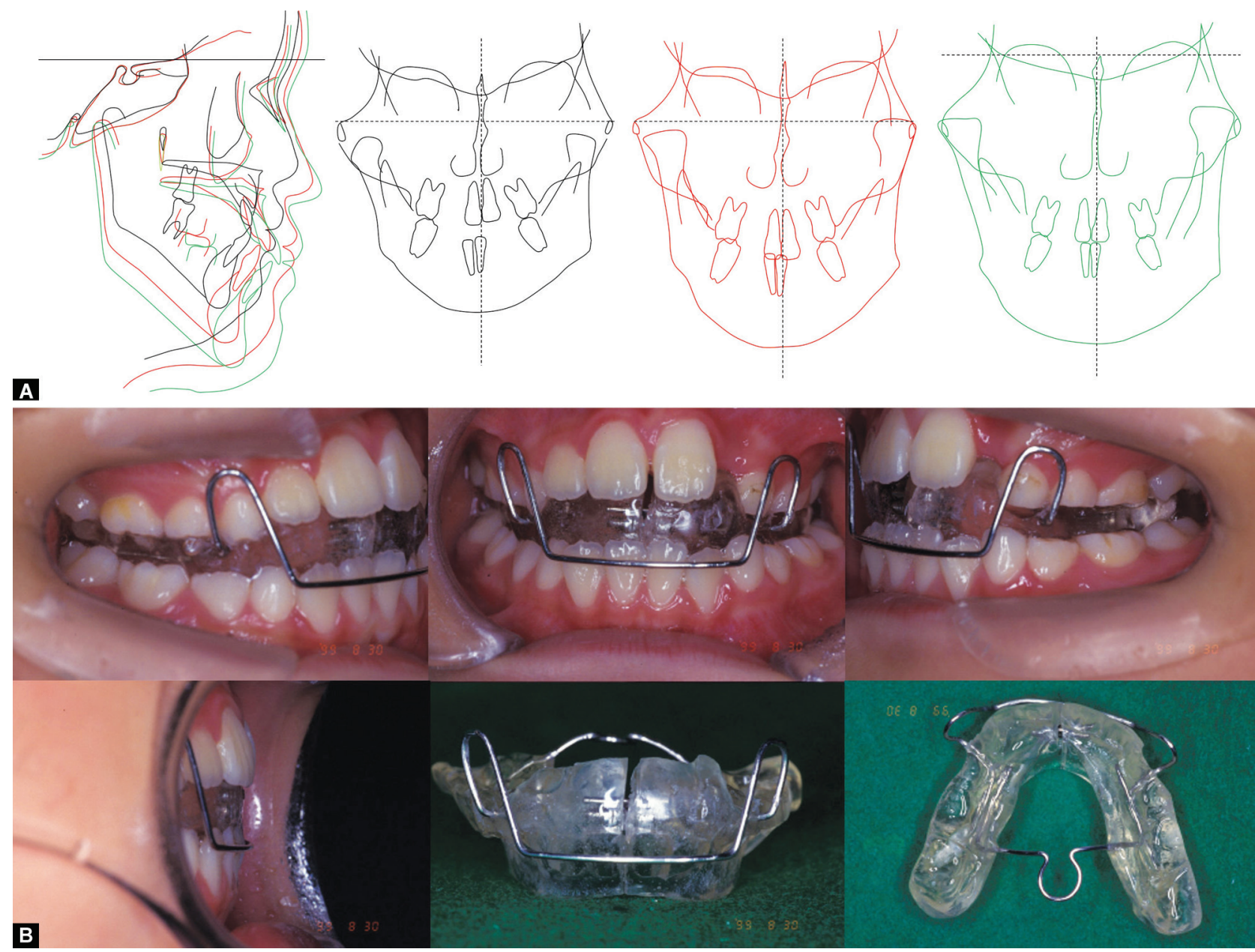

Figs $2 \mathrm{~A}$ and B: (A) Lateral and frontal cephalometric tracings before treatment (black line, 6 years 4 months), after first phase treatment (red line, 11 years 5 months), and at posttreatment (green line, 15 years 3 months). (B) Functional alliance used in first phase treatment

treatment of 4 years and 6 months (at the age of 11 years and 5 months), her facial profile remained to be straight type with mandibular asymmetry caused by lymphangioma (Fig. 3A). All her permanent teeth except the maxillary second molars had erupted (Fig. 3B and D). The mandibular dental midline shifted to the right $(2.0 \mathrm{~mm})$ with lingually inclined lower left molars. This may have been caused by the hygroma growth. The patient exhibited moderate crowding around lower incisors and the upper left canine, and the overjet and overbite were $+1.0 \mathrm{~mm}$ and $+1.4 \mathrm{~mm}$, respectively. From the model analyses, molar relationships were improved to Angle Class I on both sides and the arch length discrepancies were $-2.0 \mathrm{~mm}$ in the maxillary arch and $-1.5 \mathrm{~mm}$ 

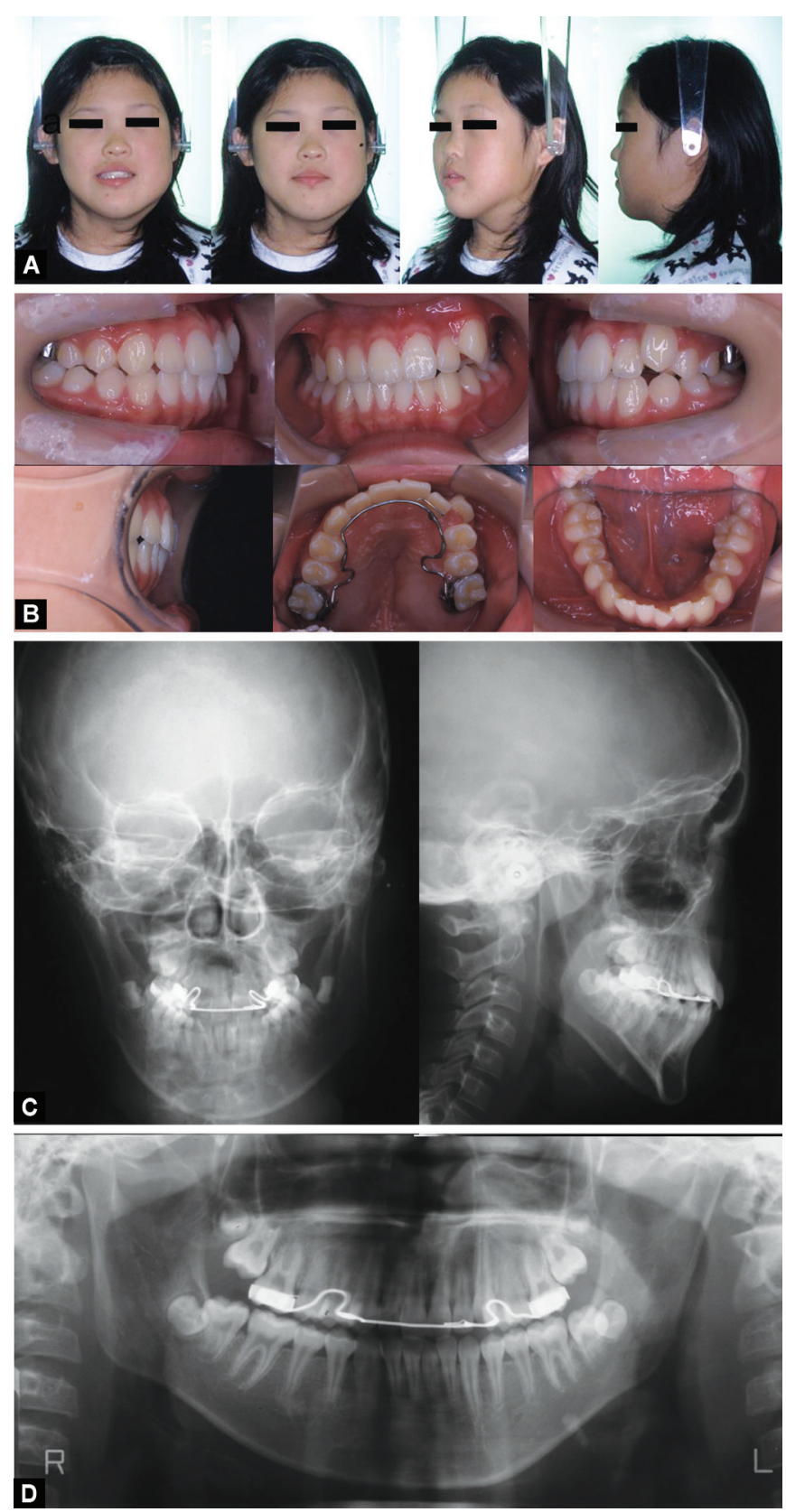

Figs $3 A$ to D: Facial (A) and intraoral photographs (B), frontal and lateral cephalograms $(C)$, and panoramic radiograph (D) after first phase treatment at the age of 11 years 5 months

in the mandibular arch. Lateral cephalometric analysis indicated a skeletal Class III jaw-base relationship with a hyperdivergent growth pattern (Figs 2A and 3C, Table 1). The mandibular central incisors were inclined lingually. The frontal cephalogram showed considerable deformation and deviation of the mandible to the left (Figs 2A and 3 C). Then, at the age of 11 years and 7 months, 0.018 in pre-adjusted edgewise devices were applied on both maxillary and mandibular dentitions to correct dental midline deviation with crowding. During the multibracket treatment, Class II and Class III elastics were used at the right and left sides, respectively. After 44-month multibracket treatment at the age 15 years and 3 months, a functional occlusion with close intercuspation was established.
After removal of the appliances, lingually bonded retainers were fixed on both dentitions. Furthermore, wraparound retainers were also used for the whole day.

\section{Treatment Results}

Posttreatment intraoral photographs showed that an ideal occlusion with a functional Class I relationship and an adequate interincisal relationship was accomplished (aged 15 years and 3 months) (Fig. 4B). Facial asymmetry caused by cystic lymphangioma remained present and her facial profile was kept to be straight type with an adequate lips position (Fig. 4A). In panoramic radiograph, root parallelism was almost achieved except for the maxillary left second premolar, but the maxillary and mandibular bilateral third molars had not yet erupted (Fig. 4C) Posttreatment cephalometric evaluation revealed a skeletal Class III jaw-base relationship (ANB $1.7^{\circ}$ ) due to the forward and downward growth of the mandible (Figs 2A and 4C; Table 1). Both the upper and lower central incisors were labially inclined (U1-FH, 123.1 ${ }^{\circ}$; L1-Mand. pl., 82.9 $)$ with an acceptable interincisal relationship. Frontal cephalogram revealed the mandibular deviation to the right; however, the dental midline deviation was improved (Fig. 4CD). The occlusal cant was maintained at $1^{\circ}$.

After a 3-year retention period, aged 18 years and 2 months, an acceptable occlusion was maintained. However, her facial asymmetry which was caused by lymphangioma had not changed (Figs 5A and 5B). Cephalometric analysis showed that the mandible had grown considerably in the downward direction, resulting in an increment of the SNB angle by $0.5^{\circ}$ which in turn resulted in a $0.5^{\circ}$ reduction of the ANB angle (Figs $5 \mathrm{C}$ and $5 \mathrm{E}$; Table 1). During the retention period, bilateral mandibular third molars had erupted and only the right third molar was extracted (Fig. 5D). MRI taken, when she was aged 22 years and 5 months, showed that the maxillary and mandibular left third molars were present proximate to the lymphangioma tumor, which means that the extraction of third molars will hold higher risks of infection and hemorrhage in the tumor, leading to airway obstruction (Fig. 5F).

After 10-year of retention, aged 25 years and 2 months, an adequate occlusion with functional Class I relationship was well maintained without crowding of the lower anterior teeth, indicating long-term stability of the occlusion, while facial asymmetry with mandibular deviation was still present (Figs 6A and 6B). Cephalometric analysis showed that the mandible had slightly grown in downward direction, resulting in an increase of FMA by $2.0^{\circ}$ (Figs $5 \mathrm{E}$ and 6C; Table 1). Frontal cephalometric analysis showed no impairment of the mandibular deviation, and the occlusal cant remained at $1^{\circ}$ (Figs $5 \mathrm{C}$ and $6 \mathrm{C}$ ). Finally, panoramic radiograph showed little change through the retention period (Fig. 6D).

\section{Discussion}

In this study, we reported an adolescent case of mandibular deviation due to congenital cervical lymphangioma treated successfully with traditional orthodontic techniques and described the challenging strategy associated with early orthodontic management. Furthermore, we conducted an 18-year follow-up of the patient including a 10 -year retention period to evaluate the treatment outcome and stability in the long term.

Guruprasad et al. ${ }^{9}$ reported that cystic lymphangioma or cystic hygroma is commonly present in the head and neck cervical areas, especially in the posterior triangle (75-80\%), due to the extensive lymphatic presence. Furthermore, the infiltrative nature 

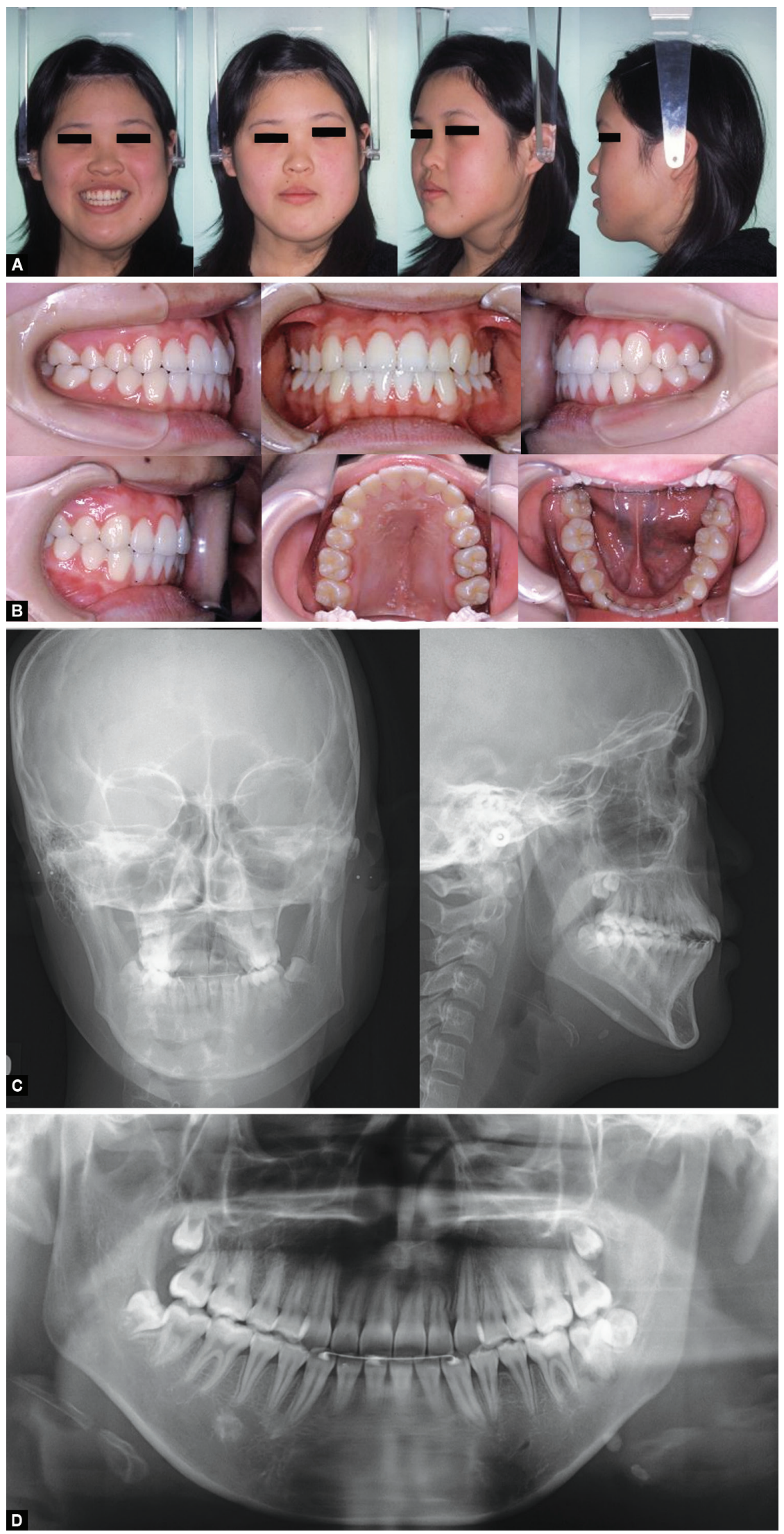

Figs 4A to D: Posttreatment facial (A) and intraoral photographs (B), frontal and lateral cephalograms (C), and panoramic radiograph (D) at the age of 15 years 3 months 

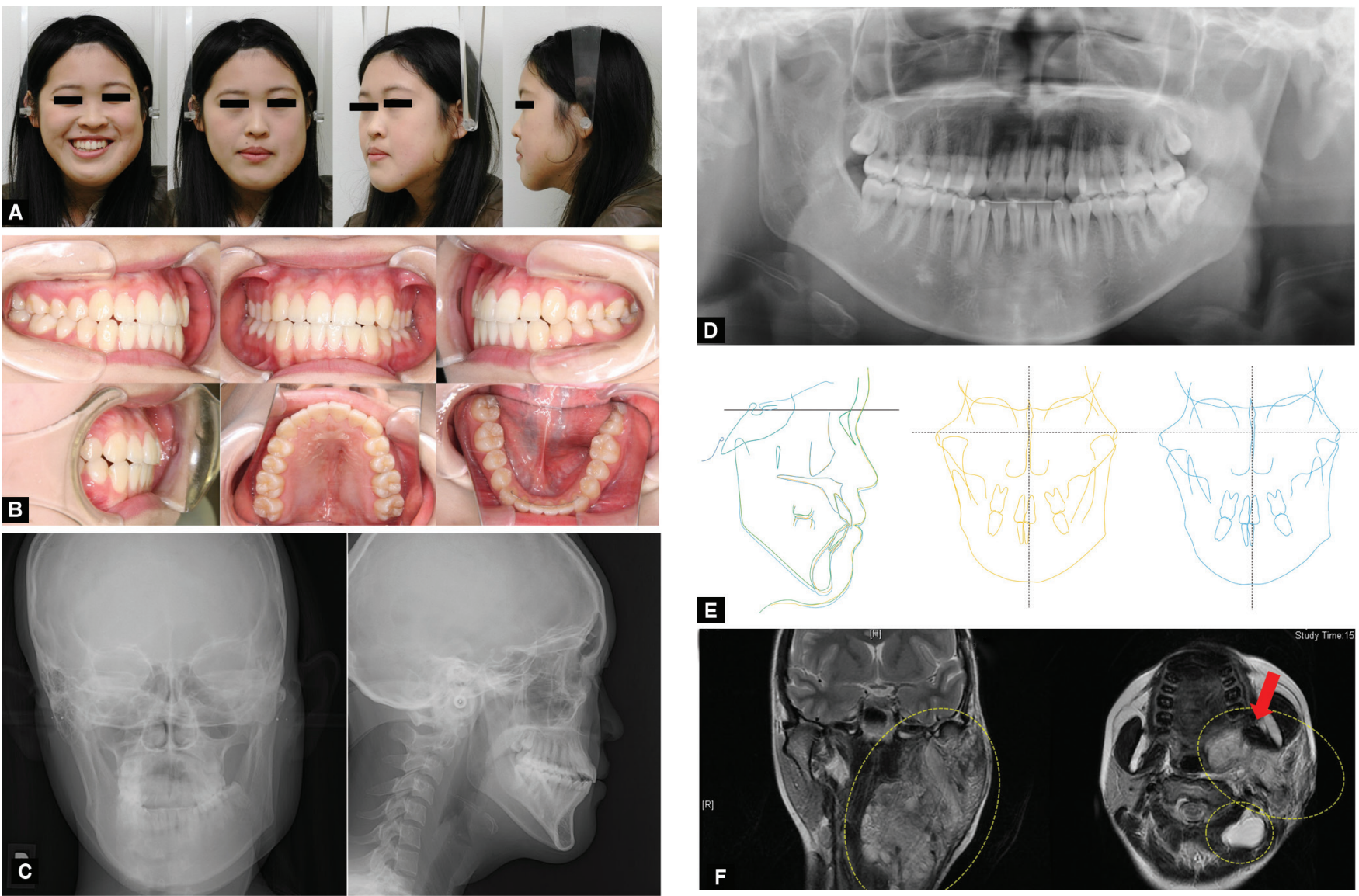

Figs $5 \mathrm{~A}$ to $\mathrm{F}$ : Facial (A) and intraoral photographs (B), frontal and lateral cephalograms (C), and panoramic radiograph (D) after 3 years retention at the age of 18 years 8 months. (E) Lateral and frontal cephalometric tracings after treatment (green line, 15 years 3 months), after 3 years retention (orange line, 18 years 2 months), and after 10 years retention (blue line, 25 years 2 months). (F) Magnetic resonance images of lymphangioma taken at the age of 22 years 5 months. Dotted yellow lines indicate tumor body; red arrow indicates the area of the left third molar

of hygromas through its fluids allows it to spread easily from the posterior cervical area into the anterior compartment of neck. ${ }^{10}$ Hence, cystic hygroma in the cervical region can induce dysphagia, airway obstruction, and breathing disability in which immediate surgical reduction would be needed. ${ }^{9,11}$ Although surgical tumor excision is the best remedy for management, the infiltrative hygromas have a much higher risk of incomplete excision, surgical sequel of neural injury, persistent lymphedema, lymphocele, and lymphorrhoea which would be worse than the presence of the tumor itself. ${ }^{9}$ The present case showed a marked facial asymmetry caused by the cystic lymphangioma, but fortunately minimal symptoms of airway obstruction, sleep apnea, dysphagia, and neural encroachment appeared throughout the orthodontic treatment. All surgical procedures such as third molar extraction were avoided to preventing infection and hemorrhage in the tumor, and since her maxillomandibular growth could be well controlled, early orthodontic management without surgical procedures was selected. The management of mandibular deviation cases involves some of the most challenging treatment planning decisions. Cases with mild mandibular deviations caused by a functional shift can be treated with minor occlusal adjustments; however, cases with severe deviations need orthodontic treatment and sometimes surgery in order to achieve a functional occlusion. ${ }^{12}$ Posterior crossbite cases with lateral mandibular shift can be distinguished as latero-occlusion. Without treatment, a posterior crossbite and latero-occlusion during growth periods may result in an asymmetric mandibular growth. ${ }^{13}$ Several reports demonstrated that mild or moderate cases of latero-occlusion can be successfully treated with functional appliances. ${ }^{14,15}$ In the present case, we used a functional appliance with an expander to improve latero-occlusion and prevent asymmetric mandibular growth caused by extension of the lymphangioma. The occlusion remained stable throughout the 10-year retention period with minimal facial change.

In our case, although the early orthodontic treatment including functional appliance was effective to regulate her maxillomandibular growth, the mandibular dental and skeletal midlines were not completely matched up to the maxillary and facial midlines, and facial asymmetry remained after first phase treatment. After initial leveling by the multibracket appliance, in order to reduce the mandibular deviation, Class II and Class III intermaxillary elastics were placed between the maxillary left first molar and mandibular left canine and between the maxillary right canine and mandibular right first molar, respectively. This resulted in the mandibular dental midline matching up to the maxillary dental and facial midlines. The possible explanation for this treatment outcome is that the maxillary left molars and the mandibular right 

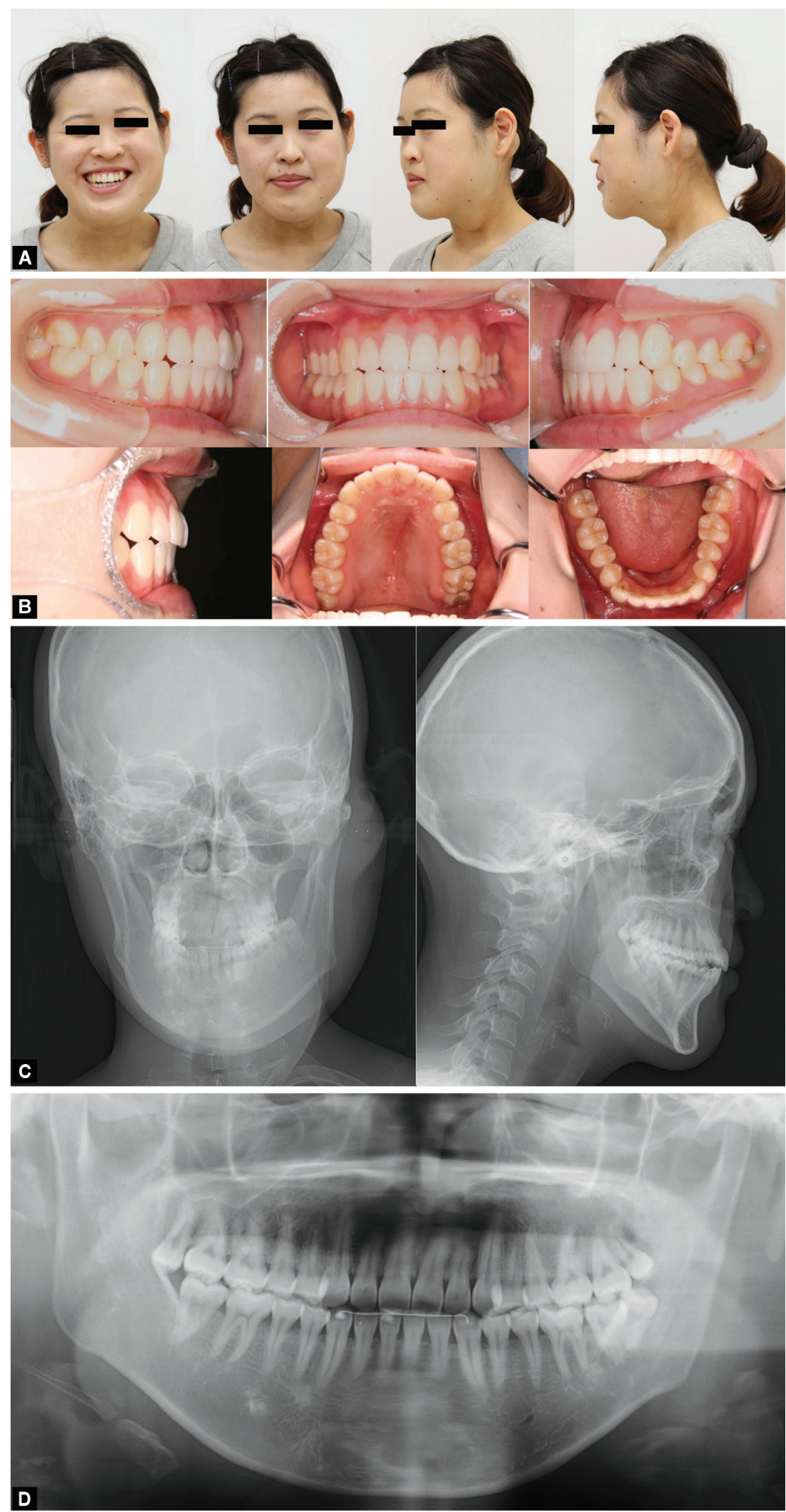

Figs 6 A to D: Facial (A) and intraoral photographs (B), frontal and lateral cephalograms (C), and panoramic radiograph (D) after 10 years retention at age 25 years and 2 months 
molars were extruded by using intermaxillary elastics, resulting in maintaining the occlusal cant. Therefore, it is suggested that in such clinical situations, the hybrid technique combining functional appliance and intermaxillary elastics can be an effective therapy for correcting the occlusal cant and mandibular deviation caused by hemifacial macrosomia.

\section{CONCLUSION}

The present article showed the longitudinal monitoring of a patient with mandibular deviation caused by congenital cervical lymphangioma after successfully treating it with traditional orthodontic techniques. After which, an acceptable occlusion with a functional Class I relationship and adequate interincisal relationship were accomplished. Throughout the 10-year retention period, a functional occlusion was well maintained without relapse, indicating a long-term occlusal stability. Taken into consideration, conventional orthodontic techniques might enable functional and stable occlusions even in patients with mandibular deviation caused by congenital cervical lymphangioma, although only early orthodontic management by itself may have some limitations. In addition, this case report also presented the benefits of long-term observation of a patient with congenital cervical lymphangioma to manage the considerable downward growth of the mandible which happens after growth spurts.

\section{Declarations}

\section{Author Statement}

AM-O, SH, RM, and KM contributed to planning of orthodontic treatment, performing orthodontic treatment and editing the manuscript. SH, RS, and AY contributed to performing case analyses and orthodontic treatment. $\mathrm{MA}, \mathrm{MH}$, and $\mathrm{ET}$ contributed to writing and editing the manuscript. All authors read and approved the final manuscript.

\section{Consent for Publication}

Written informed consent was obtained from the patient for publication of this case report and any accompanying images.

\section{References}

1. Grasso DL, Pelizzo G, Zocconi E, et al. Lymphangiomas of the head and neck in children. Acta Otorhinolaryngol Ital 2008;28(1):17-20.
2. Perkins JA. New frontiers in our understanding of lymphatic malformations of the head and neck: natural history and basic research. Otolaryngol Clin North Am 2018;51(1):147-158. DOI: 10.1016/j.otc.2017.09.002.

3. Sun RW, Tuchin VV, Zharov VP, et al. Current status, pitfalls and future directions in the diagnosis and therapy of lymphatic malformation. J Biophoton 2018;11(8):e201700124. DOI: 10.1002/ jbio.201700124.

4. Wiegand S, Eivazi B, Barth PJ, et al. Pathogenesis of lymphangiomas. Virchows Arch 2008;453(1):1-8. DOI: 10.1007/s00428-008-0611-z.

5. Chung CJ, Hwang S, Choi YJ, et al. Treatment of skeletal openbite malocclusion with lymphangioma of the tongue. Am J Orthod Dentofacial Orthop 2012;141(5):627-640. DOI: 10.1016/ j.ajodo.2010.07.029.

6. Souki BQ, Figueiredo DS, Lima IL, et al. Two-phase orthodontic treatment of a complex malocclusion: giving up efficiency in favor of effectiveness, quality of life, and functional rehabilitation? Am J Orthod Dentofacial Orthop 2013;143(4):547-558. DOI: 10.1016/ j.ajodo.2012.02.027.

7. Farronato M, Fama A, Lanteri $V$, et al. Lymphangioma of the tongue associated with open bite: case report. Eur J Pediatr Dent 2019;20(4):311-314. DOI: 10.23804/ejpd.2019.20.04.10.

8. Wada K, Matsushita K, Shimazaki S, et al. An evaluation of a new case analysis of a lateral cephalometric roentgenogram. J Kanazawa Med Univ 1981;6:60-70.

9. Guruprasad Y, Chauhan DS. Cervical cystic hygroma. J Maxillofac Oral Surg 2012;11(3):333-336. DOI: 10.1007/s12663-010-0149-x.

10. Toranzo JM, Guerrero F, Dibildox J, et al. A congenital neck mass. Oral Surg Oral Med Oral Pathol Oral Radiol Endod 1996;82(4):363-364. DOI: 10.1016/s1079-2104(96)80298-8.

11. Hamoir M, Renacle M, Youssif A, et al. Surgical management of parapharyngeal cystic hygroma causing sudden airway obstruction. Head Neck Surg 1988;10(6):406-410. DOI: 10.1002/ hed.2890100608.

12. Rubenduz M, Uslu O. Functional treatment of an asymmetry case having left side paralysis: a case report. Eur J Dent 2010;4(3):341-347.

13. Graber TM. Treatment of class III malocclusions. In: Graber TM, Rakosi T, Petrovic AG, editors. Dentofacial orthopedics with functional appliances. 2nd ed. St. Louis: Mosby; 1997. p. 461-480.

14. Ito A, Tachiki K, Shioyasono R, et al. Management of hemifacial microsomia caused by the first and second branchial arch syndrome with orthodontic approach. J Contemp Dent Pract 2020;21(10):11891195. PMID: 33686045.

15. Yamada H, Sawada M, Tanaka E. A case report of hemifacial mircosomia treated with conventional orthodontic technique: a long-term follow-up. J Am Dent Assoc 2021:S0002-8177(20)30782-0. DOI: 10.1016/j.adaj.2020.10.015. 